\title{
Diversidad de bacterias en cicadélidos vectores potenciales de Xylella fastidiosa Wells et al. en cafetos en Puerto Rico ${ }^{1,2}$
}

\author{
Yobana Mariño-Cárdenas $s^{3}$ y Mildred Zapata
}

\author{
J. Agric. Univ. P.R. 93(1-2):101-121 (2009)
}

\begin{abstract}
RESUMEN
Se aislaron bacterias de la cabeza y el cuerpo de tres especies de vectores potenciales de la bacteria Xylella fastidiosa (Xf): Apogonalia spp., Hortensia similis y Caribovia coffeacola, en el medio de cultivo 'periwinkle wilt' (PW). Éstas se caracterizaron mediante ácidos grasos en 19 géneros, los cuales se dividieron en cuatro grupos de acuerdo al tejido del insecto. Curtobacterium, Micrococcus y Pasteurella se identificaron sólo en la cabeza. Brevundimonas, Paenibacillus, Pantoea, Providencia, Rhizobium y Vibrio se detectaron en los tejidos internos. Acinetobacter, Chryseobacterium, Clavibacter, Kluyvera, Kokuria, Nocardia, Pectobacterium y Pseudomonas se identificaron en los tejidos externos. Bacillus y Microbacterium se aislaron en todos los tejidos. La mayoría de estas bacterias han sido reportadas como agentes de control biológico de plagas y otras como patógenas en otros huéspedes. De estos géneros el único que ha sido informado asociado antagónicamente con Xf es Curtobacterium; esta bacteria fue aislada del insecto $H$. similis. También, de las fincas donde se colectaron los insectos se aislaron bacterias de cafetos que mostraban enrizamiento de los bordes de las hojas. Estas bacterias se identificaron en nueve géneros mediante el sistema BIOLOG $\otimes$. Los géneros más frecuentes fueron Bacillus, Micrococcus y Staphylococcus. En menor frecuencia se encontraron: Arthrobacter, Chryseobacterium, Clavibacter, Enterobacter, Rhizobium y Sphingobacterium. La mayoría de estos géneros han sido reportados como endófitos en otros cultivos. Los géneros de bacteria presentes en insectos y plantas fueron BaciIlus, Chryseobacterium, Clavibacter, Micrococcus y Rhizobium. Todas las bacterias Gram negativas se evaluaron para detectar la presencia de Xf mediante la prueba de ELISA. Se detectó Xf en cuatro aislamientos provenientes de $C$. coffeacola y $H$. similis, pero no se logró aislar la bacteria en PW para su confirmación final.
\end{abstract}

Palabras clave: insectos vectores, Apogonalia, Caribovia coffeacola, Hortensia similis, café, xilema

${ }^{1}$ Manuscrito sometido a la Junta Editorial el 12 de marzo de 2008.

${ }^{2}$ Esta investigación fue financiada por el proyecto ZTS-16 (USDA/CSREES).

${ }^{3}$ Ex-estudiante Graduada, Departamento de Cultivos y Ciencias Agroambientales, Programa de Protección de Cultivos, Colegio de Ciencias Agrícolas, Univ. de Puerto RicoMayagüez.

${ }^{4}$ Catedrática e Investigadora, Departamento de Cultivos y Ciencias Agroambientales, Programa de Protección de Cultivos, Colegio de Ciencias Agrícolas, Univ. de Puerto RicoMayagüez, Call Box 9000, Mayagüez, PR. 00681. 


\begin{abstract}
Bacterial diversity in potential cicadellids vectors of Xylella fastidiosa Wells et al. in coffee plants in Puerto Rico

Bacteria from head and body tissues of three potential insect vectors of Xylella fastidiosa (Xf), Apogonalia spp., Hortensia similis and Caribovia coffeacola, were isolated in periwinkle wilt (PW) medium. They were characterized by fatty-acid methyl esters into 19 genera, which were divided into four groups according to insect tissue: Curtobacterium, Micrococcus and Pasteurella were identified only in the head; Brevundimonas, Paenibacillus, Pantoea, Providencia, Rhizobium and Vibrio were identified from internal tissues; Acinetobacter, Chryseobacterium, Clavibacter, Kluyvera, Kokuria, Nocardia, Pectobacterium and Pseudomonas were identified in the external tissues; Bacillus and Microbacterium were isolated from all tissues. The majority of these bacteria have been reported as biological control agents against many pests, and others as pathogenic bacteria in different hosts. The only genus previously reported antagonistic to Xf is Curtobacterium, which was isolated from the insect $H$. similis. Bacteria from coffee plants showing leaf curling and grown on the same farms where insects were collected, were isolated in periwinkle wilt medium. These isolates were identified into nine genera using BIOLOG $\otimes$. The most frequent genera were BacilIus, Micrococcus and Staphylococcus. Less frequent were Arthrobacter, Chryseobacterium, Clavibacter, Enterobacter, Rhizobium and Sphingobacterium. Most of these genera have been reported as endophytic bacteria in other crops. Bacteria common in both insects and plants were Bacillus, Chryseobacterium, Clavibacter, Micrococcus and Rhizobium. All Gram negative bacteria were tested for the presence of Xf by the ELISA test. Four isolates from $C$. coffeacola and $H$. similis were positive to Xf when using ELISA, but it was not possible to isolate the bacterium in periwinkle wilt medium for final confirmation.
\end{abstract}

Key words: insect vectors, Apogonalia, Caribovia coffeacola, Hortensia similis, coffee, xylem

\title{
INTRODUCCIÓN
}

La producción de café en Puerto Rico tiene un alto potencial agrícola; el café constituye el segundo cultivo de importancia económica, social, ecológica e hidrográfica de la zona montañosa (Monroig, 2007). La producción de café para el año 2006-07 tuvo un valor de \$53.4 millones. El café aportó el $16.2 \%$ del valor total de las cosechas en Puerto Rico (Departamento de Agricultura de Puerto Rico, 2008). Mundialmente existe una gama de enfermedades que pueden causar pérdidas económicas importantes en el café. Una de estas enfermedades es conocida como el encorchado de las hojas del café o "crespera" (Li et al., 2001; Vargas et al., 2002; Redak et al., 2004). Los síntomas que se manifiestan morfológicamente en la planta varían desde hojas alargadas y estrechas con márgenes ondulados y necrosados, entrenudos cortos, y formación de grupos de hojas terminales. Las inflorescencias se tornan de color verdoso, hay una reducción del tamaño y cantidad de frutos, y la producción disminuye significativamente. Una planta puede presentar 
ramas con síntomas severos y ramas aparentemente sin síntomas (Beretta et al., 1996; Meneguim et al., 2001; Li et al., 2001; Vargas et al., 2002). Cuando la enfermedad está avanzada se observa un alto grado de defoliación, debilitamiento general y muerte de la planta. El agente causal de la crespera es la bacteria Xylella fastidiosa (Xf) (Wells et al., 1987) que corresponde a organismos Gram-negativos que se reproducen asexualmente por fisión binaria (Bradbury, 1991). Xylella pertenece a la división Gracilicutes, subdivisión Proteobacteria y es difícil de crecer en medios de cultivo (Mizell et al., 2003). Reside en los vasos del xilema de las plantas hospederas, con temperatura óptima entre 26 y $28^{\circ} \mathrm{C}$ y pH óptimo para crecimiento de 6.5 a 6.9 (Rodríguez, 2003). Esta bacteria sólo puede ser transmitida por insectos que se alimentan del xilema de las plantas, familias Cicadellidae y Cercopidae (Hopkins, 1989; Lopes, 1996; Almeida y Purcell, 2003; Redak et al., 2004; Brodbeck et al., 2006). El primer informe de infección de esta bacteria en café fue realizado por Beretta en 1995, en el estado de Sao Paulo en Brasil (Rodríguez, 2003). En Costa Rica y Brasil, Xf ha sido reportada ocasionando ataques severos en siembras de café. De igual manera, en Brasil se ha demostrado que la raza de Xf que se ha considerado capaz de infectar los cafetos es transmitida por el saltahojas Dilobopterus costalimai (Cicadellidae: Cicadellinae) (Céu et al., 2006; Li et al., 2001). Por otro lado, existe otra condición que se ha denominado con el nombre de crespera que afecta el café en Colombia. Los síntomas son parecidos a los que causa Xf ya que también afecta el balance hormonal, pero en este caso se ha podido demostrar que el agente causal es un fitoplasma. A diferencia de Xf, que ataca el xilema, el fitoplasma ataca los vasos del floema (Galvis et al., 2007). La enfermedad, causada por el fitoplasma y descrita desde hace más de 60 años (Urhan, 1950), normalmente no reduce los rendimientos significativamente. La confirmación del fitoplasma como agente causal se demostró en el 2007; representa el primer fitoplasma en café y pertenece al grupo16 SrIII.

En Puerto Rico se ha detectado la presencia de algunos vectores potenciales de Xf en plantaciones de café y cítricos, tales como Apogonalia spp., Caribovia coffeacola (Dozier), Caribovia coffeaphila (Dozier), Hortensia similis (Walker) y Leocomiapsis scaramuzzai (Metcalf y Bruner) (Brodbeck y Andersen, 2006; Brodbeck et al., 2006; Mariño et al., 2007; Mariño, 2007). Al presente no existen datos sobre la capacidad de estos insectos para portar la bacteria.

La identificación de vectores de Xf es complicada por el bajo número de bacterias presentes en los insectos, lo que dificulta la detección mediante técnicas inmunológicas, tales como ELISA y PCR (Nomé et al., 1980). El aislamiento, en algunas ocasiones, se convierte en una herramienta de confirmación definitiva (Mundell, 2005). 
El propósito de esta investigación fue identificar las poblaciones bacterianas que prevalecen en la cabeza y cuerpo de Hortensia similis Walker, Caribovia coffeacola Dozier y Apogonalia spp., distinguir las bacterias que están asociadas a la cabeza y parte del intestino anterior de los insectos, y comparar con la diversidad bacteriana presente en el tejido vascular de cafetos en las fincas donde se coleccionaron los insectos.

\section{MATERIALES Y MÉTODOS}

Las muestras de insectos se colectaron en tres fincas cafetaleras de Puerto Rico: las dos primeras en Yauco y la tercera en Adjuntas. La primera, Villa Cecilia, localizada en la carretera 372 (latitud $18^{\circ} 08^{\prime} 1.2^{\prime \prime} \mathrm{N}$ y longitud $66^{\circ} 50^{\prime} 2.7^{\prime \prime W}, 795 \mathrm{~m}$ de altitud); la segunda, Sierra Alta, situada en la carretera 375 (latitud $18^{\circ} 06^{\prime} 13.4$ "N y longitud $66^{\circ} 49^{\prime} 42.7^{\prime \prime W}, 412 \mathrm{~m}$ de altitud); y la tercera en Adjuntas, en la carretera 526 (latitud $18^{\circ} 13^{\prime} 12.1^{\prime \prime} \mathrm{N}$ y longitud $66^{\circ} 45^{\prime} 55.6^{\prime \prime} \mathrm{W}, 637 \mathrm{~m}$ de altitud). De igual manera, las muestras de tejido vegetal de plantas aparentemente enfermas se colectaron en cuatro fincas, en las tres fincas anteriores y en una cuarta ubicada en Juana Díaz, carretera 317 (latitud $18^{\circ} 8^{\prime} 37.4 ” \mathrm{~N}$ y longitud $66^{\circ} 51^{\prime} 19.4^{\prime \prime} \mathrm{W}, 495 \mathrm{~m}$ de altitud).

\section{Colección de Insectos}

De abril a noviembre de 2006 se realizaron seis colecciones de insectos de tres especies reportadas como vectores potenciales de Xf para Puerto Rico (Brodbeck et al., 2006; Mariño et al., 2007; Mariño, 2007). Se usó la red entomológica de $33 \mathrm{~cm}$ de diámetro para atrapar los insectos. Los insectos se obtuvieron de diferentes hospederos: Apogonalia spp. sobre una herbácea, Momordica charantia (cundeamor); Caribovia coffeacola (Dozier) en cafetos (Coffea arabica L.); Hortensia similis (Walker) en dos herbáceas: Eleusine indica (L.) (pata de gallina) y Commelina diffusa Burm (cohítre). Las especies Apogonalia spp. y Hortensia similis se colectaron en las fincas de Yauco y C. coffeacola en Adjuntas.

\section{Aislamiento de bacterias de insectos}

Se aislaron las bacterias presentes a nivel interno y externo de los insectos Apogonalia spp., Caribovia coffeacola y Hortensia similis. Se usaron cuatro frascos con cuatro ejemplares por especie, cada grupo constituyó un tratamiento y cada tratamiento consistió de tres repeticiones: 1) cuerpo completo (incluyendo la cabeza) desinfestado; 2) cuerpo completo sin desinfestar; 3 ) cabeza (aparato bucal y parte del intestino anterior) desinfestada; y 4) cabeza sin desinfestar. 
Los tratamientos de cuerpo y cabeza desinfestados consistieron de inmersiones sucesivas de insectos completos en etanol al 90\%, hipoclorito de sodio al $2 \%$ y tres lavados con agua destilada estéril, cada uno por un minuto (Hill y Purcell, 1995). Para el aislamiento de bacterias a partir de la cabeza, se usó el estereoscopio para separar la cabeza tratando de incluir el aparato bucal y parte del intestino anterior, tejido donde puede residir Xf (Blake et al., 2004; Almeida y Purcell, 2003).

Para el cultivo de las bacterias provenientes de cabeza y cuerpo, desinfestados y sin desinfestar, se maceró y colocó el tejido por 30 minutos en frascos que contenían agua destilada esterilizada y $100 \mu \mathrm{l}$ de caldo de medio 'Periwinkle wilt' (PW), el cual es selectivo para el crecimiento de bacterias de tipo fastidioso (Schaad et al., 2001). Luego, se dispersaron dos gotas de $20 \mu \mathrm{l}$ de la suspensión en medio sólido de PW (Almeida y Purcell, 2003; Newman et al., 2004). Las placas se mantuvieron a $27^{\circ}$ $\mathrm{C}$ en la incubadora (Precision Scientific $\left.{ }^{\circledR}\right)^{5}$ por 30 días y se registraron las colonias bacterianas cada 48 horas.

\section{Aislamiento de bacterias de café}

De septiembre a noviembre de 2006 se realizaron tres colecciones de tejido vegetal. En cada colección se tomaron tres ramas de 15 plantas al azar, colectando muestras principalmente de aquellas plantas que mostraron síntomas característicos de Xf tales como defoliación, clorosis, y hojas arrugadas en los bordes. No se observaron síntomas se alargamiento de hojas ni inflorescencias color verdoso.

De las tres ramas colectadas se seleccionaron cinco hojas; cada una de éstas se limpió con un cepillo y jabón para eliminar al máximo organismos presentes en las partes externas y posibles contaminantes. Se cortó un trozo de $3 \mathrm{~cm}$ de la parte de la vena principal y pecíolo. Este tejido se desinfestó mediante inmersiones sucesivas de un minuto en etanol al 70\%, luego en hipoclorito de sodio (clorox comercial al 20\%) y tres lavados con agua destilada estéril.

Para el cultivo de las bacterias internas localizadas en dichos tejidos vegetales, cada uno de los trozos desinfestados se cortó en trozos de 1 mm aproximadamente. Éstos se colocaron en $2 \mathrm{ml}$ de medio líquido $\mathrm{PW}$ por espacio de 30 minutos a temperatura ambiente y 24 horas en nevera $\left(4^{\circ} \mathrm{C}\right)$. Luego se dispersó $100 \mu \mathrm{l}$ en platos petri con medio de cultivo $\mathrm{PW}$ sólido y se colocaron en incubadora a $28^{\circ} \mathrm{C}$ por 30 días, registrándose las colonias presentes cada 48 horas.

\footnotetext{
${ }^{5}$ Las marcas registradas sólo se usan para proveer información específica y su uso no constituye garantía por parte de la Estación Experimental Agrícola de la Universidad de Puerto Rico ni endoso sobre otros productos o equipo que no se mencionan.
} 


\section{Caracterización de bacterias}

Todas aquellas colonias que presentaron características morfológicas diferentes (color, tamaño, configuración, borde y elevación) se purificaron realizando tres transferencias consecutivas, la primera en PW $\mathrm{y}$, debido a que las colonias crecieron rápido, las otras dos se hicieron en medio agar de levadura, dextrosa y carbonato de calcio (YDCA, por sus siglas en inglés). Posteriormente, las bacterias se caracterizaron mediante tinción diferencial Gram, pruebas de catalasa y oxidasa y tinción de esporas para las bacterias Gram positivas (Schaad et al., 2001).

\section{Identificación de desconocidos bacterianos}

\section{a. Análisis de ácidos grasos (CG-FAME)}

Se obtuvieron 178 aislamientos de bacterias de los tejidos de los insectos y entre ellos se seleccionaron 53 que presentaron características morfológicas y quimiotaxonómicas diferentes. Éstos se transfirieron a frascos con $2.5 \mathrm{ml}$ de medio de cultivo agar de tripticasa soya (TSA) sólido (Kunitsky, 2006) y se incubaron por un período de 24 horas a $28^{\circ} \mathrm{C}$ en la incubadora. Luego de este periodo se enviaron a identificar al Laboratorio de identificación de bacterias y análisis de ácidos grasos del departamento de Patología de Plantas de la Universidad de Florida.

\section{b. Sistema BIOLOG®}

De las plantas se obtuvieron 68 aislamientos que se organizaron en 12 grupos con características morfológicas y quimiotaxonómicas comunes, tales como color de la colonia, respuesta Gram, morfología celular, respuesta a la prueba de oxidasa y catalasa. A partir de éstos se tomó una bacteria representativa de cada uno, la cual se identificó utilizando el sistema de BIOLOG®.

Detección de Xf por el método ELISA-DAS en los desconocidos bacterianos Gram negativos

Se utilizó la prueba de ELISA llamada PathoScreen-Xf (Agdia, Inc., Elkhart, IN) para la detección de Xf. Para los cultivos puros, se tomaron dos alícuotas de $1 \mu \mathrm{l}$ de crecimiento bacteriano. Los cultivos puros se suspendieron en $600 \mu \mathrm{l}$ de amortiguador de extracción contenidos en frascos de $1.5 \mathrm{ml}$; para asegurar la homogeneidad de la dilución cada uno de los frascos se agitó usando el vórtex por un periodo no menor de tres minutos. Se colocaron $100 \mu \mathrm{l}$ de suspensión de cada muestra por celda. Luego se incubó en nevera $\left(4^{\circ} \mathrm{C}\right)$ por 24 horas. Posteriormente, la placa se lavó 10 veces con amortiguador fosfato salino diluido PBS-TP 
[Phosphate buffer saline + Tween $20+$ Polyvinyl pyrolidone (PVP)]. Previo a los lavados se preparó la enzima conjugada diluyendo la concentrada en PBS-TP en relación 1:4. A cada una de las celdas se le añadió $100 \mu \mathrm{l}$ de la enzima y la microplaca fue incubada a temperatura ambiente $\left(25^{\circ} \mathrm{C}\right)$ por dos horas. Nuevamente se realizaron 10 lavados con PBS- TP. Finalmente, se agregó $100 \mu \mathrm{l}$ por celda de la solución sustrato OPD ( $40 \mu \mathrm{l}$ de peróxido de hidrógeno al $30 \%$ en $100 \mathrm{ml}$ de solución) y se incubaron a temperatura ambiente por 10 minutos. La respuesta positiva se determinó mediante cambio en coloración; la respuesta se reconfirmó mediante lectura en un espectrofotómetro de Advanced Instruments, Carolina, Puerto Rico.

\section{Análisis estadístico}

Para determinar diferencias entre el número de colonias morfológicamente diferentes por especie de insecto, tejido (cabeza-cuerpo) de aislamiento y tratamiento (desinfestado y sin desinfestar), se realizó un análisis de varianza (ANOVA) de dos factores y una prueba de medias de Tukey al 5\% de significancia usando el programa de Infostat (Infostat, 2006). Por otro lado, los resultados obtenidos de la identificación de desconocidos bacterianos, mediante la secuenciación de ácidos grasos, se sometieron a un análisis de conglomerados ("cluster analysis") usando Infostat (Infostat, 2006).

\section{RESULTADOS Y DISCUSIÓN}

\section{Diversidad bacteriana en insectos}

De las tres especies de insectos se aislaron un total de 178 colonias de bacterias, de las cuales $81(45.5 \%)$ se aislaron de tejidos de $H$. similis, 46 (25.8\%) de C. coffeacola y 51 (28.7\%) de Apogonalia spp. No se registraron diferencias significativas en cuanto al número de colonias por especie de insecto ( $p>0.05$ ). En cuanto al tejido y tratamiento, se encontraron diferencias significativas entre el número de colonias presentes en los tejidos desinfestados y sin desinfestar $(\mathrm{p}<0.05)$, debido a que al desinfestar se reduce notablemente la flora bacteriana presente en cada uno de éstos. Esta disminución se notó más en la cabeza de los insectos (Cuadro 1).

En la respuesta a la tinción diferencial Gram, se observó que 82 (46.1\%) de los aislados fueron Gram negativos y 96 (53.9\%), Gram positivos. En la prueba de oxidasa, $115(64.6 \%)$ cepas respondieron de forma negativa a la prueba y $63(35.4 \%)$ fueron positivas, indicando que hay un predominio de organismos entéricos. En cuanto a la prueba de 
CUADRo 1.-Número total de cepas bacterianas por insecto en tejido de aislamiento desinfestado y sin desinfestar.

\begin{tabular}{|c|c|c|c|c|c|}
\hline \multirow[b]{2}{*}{ INSECTO } & \multicolumn{2}{|c|}{ CABEZA $^{1}$} & \multicolumn{2}{|c|}{ CUERPO $^{2}$} & \multirow[b]{2}{*}{ TOTAL } \\
\hline & $\mathrm{D}^{3}$ & $\mathrm{~S}^{4}$ & $\mathrm{D}^{3}$ & $\mathrm{~S}^{4}$ & \\
\hline Apogonalia spp. & 5 & 16 & 11 & 19 & 51 \\
\hline Caribovia coffeacola & 6 & 16 & 10 & 14 & 46 \\
\hline Hortensia similis & 3 & 31 & 23 & 24 & 81 \\
\hline TOTAL & 14 & 63 & 44 & 57 & 178 \\
\hline
\end{tabular}

${ }^{1}$ Cabeza: Aparato bucal y parte de intestino anterior.

${ }^{2}$ Cuerpo: Cuerpo completo incluyendo la cabeza.

${ }^{3} \mathrm{D}$ : Tratamiento de tejido desinfestado.

${ }^{4} \mathrm{~S}$ : Tratamiento de tejido sin desinfestar.

catalasa predominaron los organismos aeróbicos, $173(97.2 \%)$ colonias fueron positivas y tan solo 5 ( $2.8 \%$ ) fueron negativas (Cuadro 2 ).

Los 53 aislamientos caracterizados mediante análisis de ácidos grasos, de acuerdo al porcentaje de similaridad, se identificaron en 19 géneros. Se observó una mayor diversidad bacteriana en la especie $H$. similis con 11 géneros, aunque la mayoría de éstos con una baja frecuencia de aislamiento. Únicamente el género Bacillus fue común a las tres especies de insectos. A su vez, éste fue el más representativo para la especie Apogonalia spp., mientras que Microbacterium fue común en $H$. similis y $C$. coffeacola y Rhizobium común en $H$. similis y Apogonalia spp. Los géneros restantes se identificaron como exclusivos para una de las tres especies (Figura 1).

\section{Distribución de géneros bacterianos por tejido y tratamiento}

De acuerdo al análisis de conglomerados, el algoritmo de agrupamiento de mejor correlación cofenética fue el de encadenamiento completo, que mostró un valor de 0.956. Este algoritmo explica el agrupamiento de los géneros bacterianos por tipo de tejido y localización (externa, interna). En la Figura 2 se observa el dendograma generado; el corte se realizó a una distancia de 1.5 y se obtuvieron siete conglomerados.

Las siete asociaciones poseen características compartidas, lo cual permitió subdividirlos en cuatro grupos (I, II, III, IV) de acuerdo al tipo de tejido y localización (externa o interna) (Figura 2). Los grupos se denominaron: Grupo I, bacterias presentes sólo en la cabeza; Grupo II: bacterias externas que sólo se presentaron en los tejidos sin desinfectar; Grupo III: bacterias presentes únicamente en los tejidos internos (desinfestados); y el Grupo IV, bacterias presentes en la cabeza, tejidos internos y externos. De acuerdo a dicha distribución tenemos a tres gé- 
CUADRO 2.-Número total de cepas agrupadas por insecto, tejido de aislamiento y respuesta a pruebas quimiotaxonómicas.

\begin{tabular}{|c|c|c|c|c|c|c|c|c|c|}
\hline \multirow[b]{2}{*}{ Insecto } & \multirow[b]{2}{*}{$\mathrm{N}^{\circ}$ Bacterias } & \multicolumn{2}{|c|}{ Tejido $^{1}$} & \multicolumn{6}{|c|}{ Pruebas $^{2}$} \\
\hline & & Cabeza & Cuerpo & Gram- & Gram + & Oxid.- & Oxid. + & Cata. - & Cata. + \\
\hline Apogonalia spp. & 51 & 21 & 30 & 21 & 30 & 30 & 21 & 2 & 49 \\
\hline Caribovia coffeacola & 46 & 22 & 24 & 27 & 19 & 24 & 22 & 3 & 43 \\
\hline Hortensia similis & 81 & 34 & 47 & 34 & 47 & 61 & 20 & 0 & 81 \\
\hline Total & 178 & 77 & 101 & 82 & 96 & 115 & 63 & 5 & 173 \\
\hline & & $43.3 \%$ & $56.7 \%$ & $46.1 \%$ & $53.9 \%$ & $64.6 \%$ & $35.4 \%$ & $2.8 \%$ & $97.2 \%$ \\
\hline
\end{tabular}

${ }^{1}$ Tejido: Cabeza $=$ Aparato bucal y parte intestino anterior; Cuerpo = Cuerpo completo incluyendo cabeza.

${ }^{2}$ Pruebas: Gram = Tinción diferencial; Oxid = Oxidasa $;$ Cata = Catalasa $;$ - = negativo; + = positivo. 


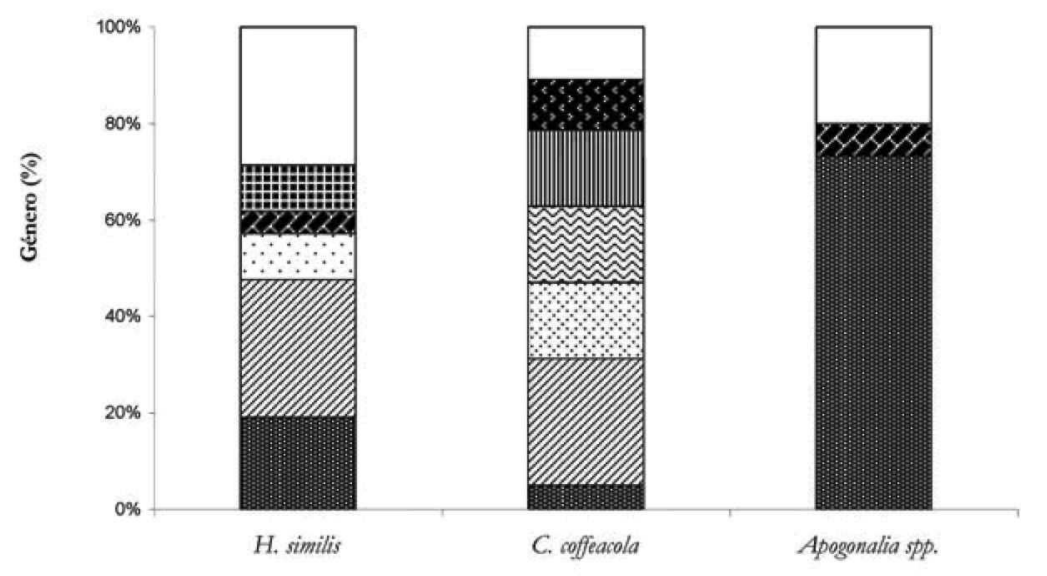

\begin{tabular}{|c|c|c|c|c|}
\hline 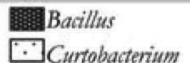 & $\begin{array}{l}\text { Macrobacterium } \\
\qquad \Delta_{\text {Rhirobitum }}\end{array}$ & $\begin{array}{l}9 \text { Protidentia } \\
\text { Vibrio }\end{array}$ & $\begin{array}{l}\text { CPasteurella } \\
\text { Paenibacillus }\end{array}$ & $\begin{array}{l}\text { 血Microcoscus } \\
\square \text { Otras }\end{array}$ \\
\hline
\end{tabular}

FIGURA 1. Distribución de géneros bacterianos en tres especies de insectos, identificados por análisis de ácidos grasos.

neros como propios de la cabeza (Grupo I), ocho externos (Grupo II) seis internos (Grupo III), y dos como presentes en todos los tejidos (Grupo IV).

Los géneros Curtobacterium, Micrococcus y Pasteurella (Grupo I) se identificaron en la cabeza, lo que teóricamente sugiere que están presentes en el aparato bucal y parte del intestino anterior de los insectos. Estos géneros son los únicos que podrían interaccionar con Xf, la cual, de estar presente, reside en estas partes de los insectos (Purcell y Hopkins, 1996; Almeida y Purcell, 2003). Vega et al. (2005) reportó a los géneros Curtobacterium y Micrococcus como bacterias endófitas en cafetos. Santos et al. (2004), encontraron algo similar en Brasil y reportaron al género Curtobacterium como común en plantas de cítricos y en la cabeza de los insectos vectores de Xf: Oncometopia faciales, Dilobopterus costalimai y Acrogonia sp. El hecho de encontrar estas bacterias en la cabeza de los insectos y a su vez en los tejidos internos de las plantas indica que los insectos las adquieren al alimentarse de los tejidos vegetales y de esa manera las transmiten de una planta a otra.

Araújo et al. (2002) y Lacava et al. (2004) encontraron a la especie Curtobacterium flaccumfaciens en mayor cantidad en los tejidos internos de plantas de cítricos que no presentaban síntomas aparentes de $\mathrm{Xf}$. Ellos concluyeron que bajo condiciones in vitro esta especie inhibe el 


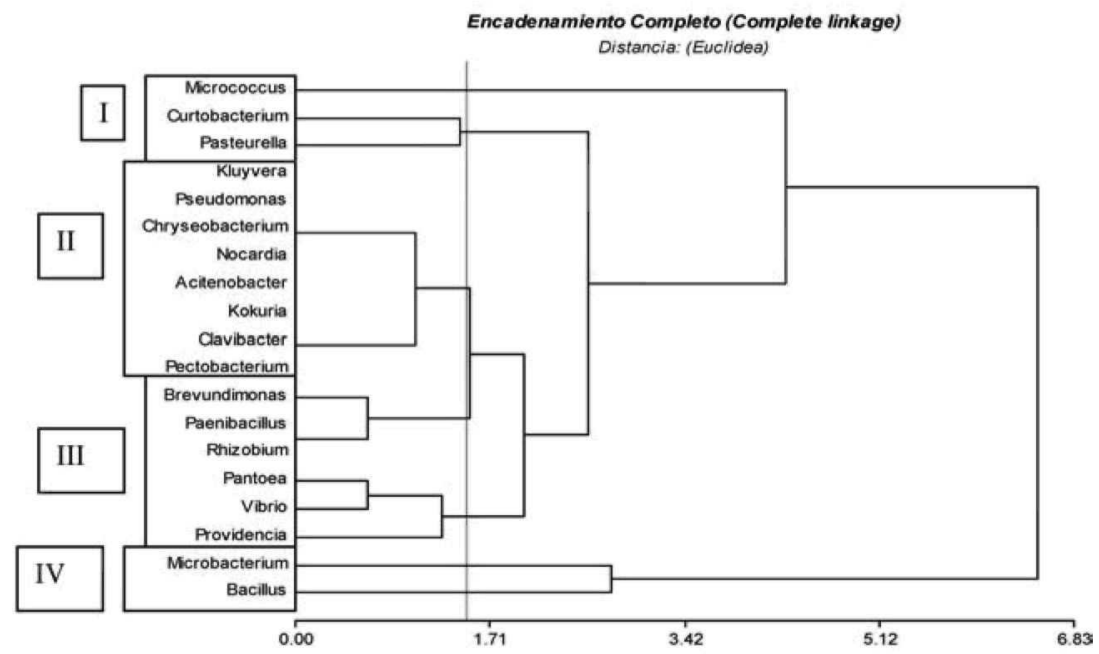

FIGURA 2. Dendograma generado con los géneros bacterianos aislados de tres especies de insectos.

desarrollo de Xylella. Dicha especie también se aisló de tejidos de cafetos y se cree que juega el mismo rol con Xylella en estas plantas (Chacón et al., 2006).

El género Micrococcus igualmente ha sido aislado de larvas de varias especies de insectos tales como: lepidópteros (Yaman et al., 2002), coleópteros (Yaman et al., 2002; Sezen et al., 2005), y dípteros (Tóth et al., 2006). A su vez, en estas investigaciones se ha evaluado su papel como controlador biológico sobre los adultos en dichas especies de insectos.

El género Pasteurella ha sido descrito mayormente como de importancia clínica en animales y humanos (Holst et al., 1992). De igual manera, ha sido aislado en poca frecuencia de la rizosfera de plantas de maíz (Lalande et al., 1989).

Dentro del Grupo II de bacterias externas se incluyeron los géneros Acinetobacter, Chryseobacterium, Clavibacter, Kluyvera, Kokuria, Nocardia, Pectobacterium y Pseudomonas. Igualmente, se tienen reportes de algunos de estos géneros en otros insectos como organismos importantes en el biocontrol de enfermedades: Acitenobacter controla a la bacteria Paenibacillus larvae (Evans y Armstrong, 2005) y Kokuria controla la roya del café (Hemileia vastratix) (Franco et al., 2006). Dentro de los géneros reportados como patógenos y que pueden ser portados por los insectos se encuentran Clavibacter (Mitchell, 2004; Van der 
Wolf et al., 2005), Pectobacterium (Lacy y Lukezic, 2003), y Pseudomonas (Martin et al., 1987; Mitchell, 2004). Por otro lado, los géneros Chryseobacterium (Cambell et al., 2004) y Nocardia (Balows et al., 1992) pueden formar relaciones mutualistas con insectos chupadores. El género Kluyvera se ha reportado como habitante común de suelo y agua, y en algunos casos ha sido de importancia clínica (Krieg y Holt, 1984). Algunas especies de este género han sido aisladas del intestino y partes externas de insectos conocidos, tal como lo es la chinche apestosa (Bell et al., 2005).

Dentro del Grupo III de bacterias internas se encontraron a los géneros Brevundimonas, Paenibacillus, Pantoea, Providencia, Rhizobium y Vibrio. Algunos de estos géneros: Brevundimonas (Tóth et al., 2006; Jaffe et al., 2001), Paenibacillus (Biliková et al., 2001; Evans, 2004; Smitley y Rothwell, 2003; Enright y Griffin, 2004) y Providencia (Spiteller et al., 2000; Kuzina et al., 2004; Tóth et al., 2006) han sido aislados de tejidos de otras especies de insectos y han sido reportados como excelentes candidatos de biocontrol de plagas. El género Pantoea se ha reportado como fitopatógeno (Bell et al., 2005; Gitaitis et al., 2003; Wells et al., 2002). El género Rhizobium se conoce mayormente por su capacidad de fijación de nitrógeno atmosférico (Zurdo et al., 2004). Especies del género Vibrio han sido descritas como de importancia clínica, ya que son agentes causales de enfermedades en humanos y animales (Balows et al., 1992).

Finalmente, los géneros Bacillus y Microbacterium (Grupo IV) estuvieron presentes en todos los tejidos internos y externos. Bacillus resultó el género más predominante en la especie Apogonalia, presente a nivel de cuerpo y cabeza, interna y externamente: Bacillus, por la presencia de endosporas, coloniza fácilmente cualquier ambiente (Schaad et al., 2001). Dicha distribución concuerda con lo observado por Tóth et al. (2006). El género Microbacterium ha sido reportado como un agente de biocontrol de malezas (Caesar y Kremer, 2004) y plagas (Bahar y Demirbag, 2007).

\section{Diversidad bacteriana en los tejidos vegetales}

En total se aislaron 68 colonias de bacterias de los cafetos, de las cuales: 17 (25\%) se obtuvieron de las plantas de Adjuntas, 17 (25\%) de Juana Díaz, 11 (16.2\%) de Yauco-Sierra Alta y 23 (33.8\%) de Yauco-Villa Cecilia. A su vez, se caracterizaron $33(48.5 \%)$ de las bacterias como Gram negativas y 35 (51.5\%), Gram positivas. En las fincas localizadas en Yauco (Villa Cecilia y Sierra Alta) se registró un mayor número de organismos Gram negativos, y en los municipios de Adjuntas y Juana Díaz predominaron los Gram positivos (Cuadro 3). Los resultados an- 
CUADRo 3.-Número total de bacterias por localidad y respuesta a pruebas quimiotaxonómicas.

\begin{tabular}{lccccccc}
\hline & & \multicolumn{6}{c}{ Pruebas } \\
\cline { 3 - 8 } Localidad & \begin{tabular}{c} 
No. \\
\cline { 3 - 8 }
\end{tabular} & Bacterias & - & $\begin{array}{c}\text { Gram } \\
+\end{array}$ & $\begin{array}{c}\text { Oxidasa } \\
-\end{array}$ & $\begin{array}{c}\text { Oxidasa } \\
+\end{array}$ & $\begin{array}{c}\text { Catalasa Catalasa } \\
-\end{array}$ \\
\hline Villa Cecilia & 23 & 14 & 9 & 12 & 11 & 0 & 23 \\
Sierra Alta & 11 & 6 & 5 & 8 & 3 & 1 & 10 \\
Juana Díaz & 17 & 7 & 10 & 11 & 6 & 2 & 15 \\
Adjuntas & 17 & 6 & 11 & 8 & 9 & 1 & 16 \\
Total/ & 68 & 33 & 35 & 39 & 29 & 4 & 64 \\
Porcentaje & & $(48.5 \%)$ & $(51.5 \%)$ & $(57.4 \%)$ & $(42.6 \%)$ & $(5.9 \%)$ & $(94.1 \%)$ \\
\hline
\end{tabular}

Leyenda: + reacción positiva, - reacción negativa.

teriores sugieren una mayor probabilidad de identificar algunos organismos patógenos en los cultivos obtenidos de Yauco-Villa Cecilia, ya que la mayoría de las bacterias fitopatógenas son Gram negativas (Hayward, 1983).

Con respecto a la caracterización bioquímica, se encontró que 39 $(57.4 \%)$ de las bacterias respondieron de forma negativa a la prueba de oxidasa; 29 (42.6\%), positiva. Asimismo, en la prueba de catalasa, 64 (94.1\%) fueron positivas; cuatro (5.9\%), negativas (Cuadro 3 ).

\section{Diversidad bacteriana en los tejidos vegetales}

A partir de los 68 aislamientos bacterianos provenientes de los tejidos vegetales de los cafetos, se formaron 12 grupos con características morfológicas y quimiotaxonómicas comunes, de estos grupos se lograron identificar mediante el sistema BIOLOG® a nueve géneros, dado su porcentaje de similitud. Se obtuvó un mayor número de géneros bacterianos en la finca localizada en Yauco-Villa Cecilia (ocho) y un menor número de Juana Díaz (cinco). Sólo tres géneros fueron comunes en los cuatro sitios; éstos fueron los de mayor frecuencia de aislamiento: $B a$ cillus (14 aislamientos), Micrococcus (11) y Staphylococcus (ocho). Con respecto a los géneros con mayor frecuencia de aislamiento por finca, se observó al género Bacillus como el más predominante en Adjuntas (cinco aislamientos) y Yauco-Villa Cecilia (cuatro). En tanto que el género Micrococcus fue dominante en Juana Díaz (cinco) y Yauco-Sierra Alta (dos). Únicamente los géneros Rhizobium y Chryseobacterium fueron aislados individualmente en una de las cuatro fincas (Figura 3).

Todos los géneros bacterianos aislados de plantas son considerados como endófitos, ya que se aislaron de superficies desinfestadas o por extracción de sus tejidos internos (Hallmann et al., 1997; Zinniel et al., 


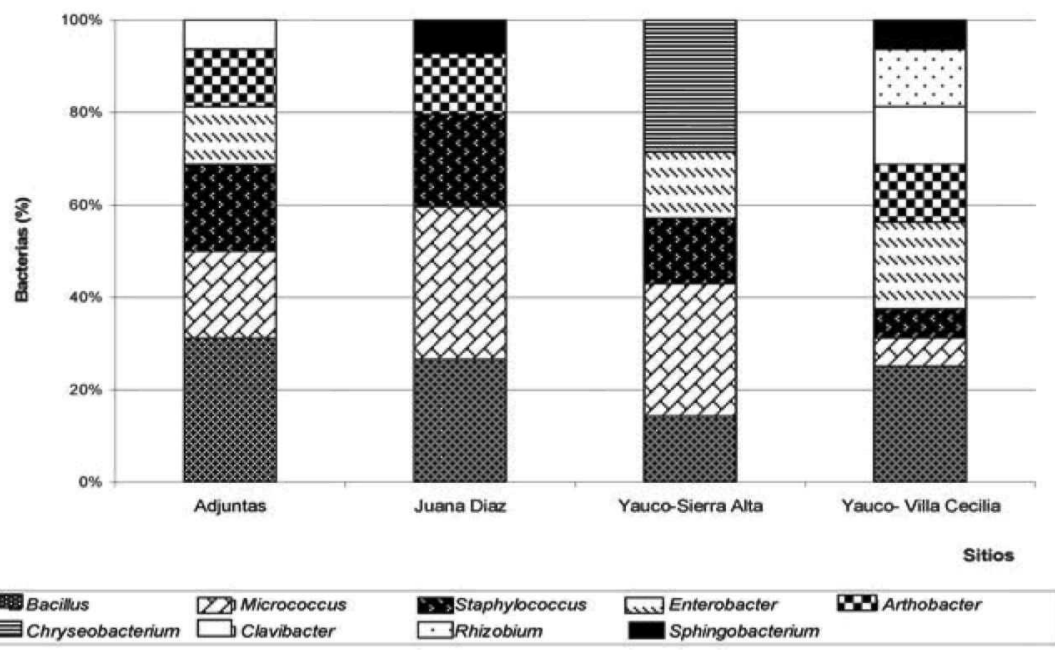

FiguRA 3. Distribución de géneros bacterianos aislados de cafetos, identificados mediante BIOLOG®.

2002; Araújo et al., 2001; Araújo et al., 2002). En general, los organismos endofitos pueden localizarse en espacios intracelulares, intercelulares o en el tejido vascular. Dicha localización presenta un nicho ecológico similar al ocupado por algunos organismos patógenos de plantas (Franco et al., 2006). Por tanto, son candidatos fuertes para ser usados como organismos de biocontrol de patógenos, insectos y nematodos (Azevedo et al., 2000; Zinniel et al., 2002).

En este estudio se aislaron nueve géneros bacterianos a partir de tejido foliar desinfestado de cafetos, C. arabica. Lacava et al. (2004), consideran que las hojas son el nicho preferencial para las bacterias endofitas. De igual manera, se determinaron a Bacillus, Micrococcus y Staphylococcus como los géneros predominantes en cuanto a su frecuencia de aislamiento. De acuerdo con Schaad et al. (2001), la mayoría de los bacilos asociados con plantas son reconocidos como patógenos, saprófitos y agentes de control biológico. Reva et al. (2002) reportan a las bacterias del género Bacillus como residentes comunes de los tejidos internos de las plantas. Algunos de estos organismos juegan un papel importante en la protección y crecimiento de las plantas. Kloepper et al. (2004). A este género bacteriano le adjudican inducir resistencia sistémica en plantas de remolacha (Beta vulgaris); proveer protección contra enfermedades por hongos, bacterias, nematodos y virus; y reducir la presencia de insectos vectores en plantaciones de tomate ( Lycopersicon esculentum) y pimiento (Capsicum annuum). 
El género Micrococcus también ha sido aislado de los tejidos internos de cafetos (Vega et al., 2005; Franco et al., 2006). Organismos de este género son considerados activos para solubilizar fósforo (Tilak et al., 2005). En esta investigación se aisló tanto de los tejidos desinfestados de las plantas como de los tejidos de los insectos.

El aislamiento del género Staphylococcus como endofito de los cafetos concuerda con lo observado por Zapata (2007), quien reporta cuatro especies de este género como bacterias endófitas frecuentes asociadas al tejido vascular de café y a su vez, tres de éstas como comunes en cultivos de cítricos.

Los seis géneros restantes, al igual que los tres anteriores, han sido reportados como endófitos en otros cultivos, tales como papa (Krechel et al., 2002), soya, sorgo, maíz (Zinniel et al., 2002) y café (Vega et al., 2005). En dichas investigaciones se ha demostrado la función de $A r$ throbacter (Gaur et al., 2004) y Sphingobacterium (Maciel, 2005) como solubilizadoras de fósforo. Otras favorecen el crecimiento de las plantas, como lo es Enterobacter (Tilak et al., 2005) y de fijación de nitrógeno como Rhizobium (Acosta y Martínez, 2002; Zurdo et al., 2004). De igual manera el género Clavibacter ha sido reportado como endófito en cafetos (Vega et al., 2005) y patógeno en otros hospederos (Balows et al., 1992; Zinniel et al., 2002).

Comparación de la diversidad bacteriana observada en los tejidos de insectos y los tejidos internos de cafetos

Sólo se encontraron cinco géneros comunes en los tejidos de los insectos y las plantas: Bacillus, Chryseobacterium, Clavibacter, Micrococcus y Rhizobium. Bacillus se aisló de todos los tejidos internos y externos de los insectos, a su vez se determinó como uno de los más dominantes dentro de los tejidos internos de las plantas. Esta distribución puede explicarse por la presencia de endosporas, que le ayudan a colonizar fácilmente cualquier ambiente (Schaad et al., 2001). Los géneros Micrococcus y Rhizobium se encontraron presentes en los tejidos internos de los insectos, el primero en la cabeza y el segundo en el cuerpo. El hecho de encontrarlos también dentro de las plantas permite inferir que estos géneros están relacionados directamente con la alimentación de los insectos y la microflora de la planta. Por otro lado, los géneros Chryseobacterium y Clavibacter se aislaron de los tejidos externos de los insectos, lo cual indica que no necesariamente las bacterias llegan a la planta mediante la alimentación de los insectos.

Determinación de la presencia de Xf mediante la prueba de ELISA

No se detectó Xylella en los aislamientos Gram negativos obtenidos a partir de los diferentes tejidos de los insectos y los tejidos vasculares 
de los cafetos. En el primer ensayo se observó una reacción positiva para cuatro de los aislamientos provenientes del cuerpo desinfestado de $H$. similis y sin desinfestar de $C$. coffeacola. Sin embargo, no se logró confirmar la reacción. Dichos aislamientos se identificaron mediante el análisis de ácidos grasos CG-FAME y se ubicaron en los géneros Providencia y Microbacterium.

La prueba de ELISA es útil cuando se requiere analizar una gran cantidad de muestras, dado que es una prueba sensitiva que no requiere equipo especializado (Costa et al., 2004). A pesar de ser sensitiva, a su vez puede dar falsos positivos debido a que está basada en anticuerpos policlonales, los cuales permiten unirse a múltiples proteínas. Este a su vez requiere altas poblaciones bacterianas, entre $10^{5}$ a $10^{6}$ UFC/ml, para su detección (Nomé et al., 1980; Wang et al., 1999). De igual manera, las poblaciones bacterianas presentes en los insectos frecuentemente son bajas (Nomé et al., 1980). Se puede inferir que en los cuatro aislamientos bacterianos positivos para la prueba de ELISA estaba presente Xf en baja concentración, lo que facilitó la proliferación de otras bacterias de crecimiento rápido que compitieron con $\mathrm{Xf}$ por el mismo nicho (Almeida y Purcell, 2003). Otra posibilidad es que se trate de una raza nueva de $X f$ que los anticuerpos no lograron detectar (Hartung et al., 1994).

La mayoría de los géneros bacterianos que aislamos de los tejidos de los insectos han sido reportados como organismos importantes de control biológico y como patógenos en otros cultivos. Futuros trabajos se deben enfocar en probar el posible potencial biocontrolador de Microbacterium, Micrococcus, Paenibacillus y Providencia. De igual manera, se debe evaluar la patogenicidad de los géneros Pantoea, Pectobacterium y Pseudomonas en los cafetos.

Los géneros Bacillus, Micrococcus y Staphylococcus se determinaron con mayor frecuencia a partir de aislamientos de los tejidos vegetales, por lo que se sugiere realizar futuros estudios para establecer la interacción de estos géneros con Xf.

No se logró aislar Xf en los cafetales de las fincas de Yauco, Juana Díaz y Adjuntas, Puerto Rico, a pesar de que existen vectores potenciales en dichas áreas. Debido a su baja concentración y dificultad de aislamiento, Xf es difícil de detectar en insectos. Este es un problema que también ha sido señalado por otros investigadores. Se infiere que Xf se encontraba en baja frecuencia y que algunas bacterias antagonistas pudieron interaccionar para mantener la población de Xf baja, lo que explicaría los falsos positivos con ELISA. Dicha inferencia se sostiene ya que se logró aislar de la cabeza de los insectos el género Curtobacterium, la cual se ha demostrado bajo condiciones in vitro y de invernadero que es antagonista de Xf. En plantas infectadas con Xf, Curtobac- 
terium suprime los síntomas de la enfermedad. Por tanto, Curtobacterium representa un potencial de control biológico a ser estudiado bajo nuestras condiciones. Por otro lado, se recomienda estar atentos a la posibilidad de introducción de otros patógenos por esquejes o plantas, como podría ser el recién identificado fitoplasma del café, y de insectos que se alimentan del floema. Afortunadamente, dicho fitoplasma no se transmite por la semilla y hasta el momento se considera endémico de ciertas localidades en Colombia.

\section{LITERATURA CITADA}

Acosta, C. y E. Martínez, 2002. Diversity of rhizobia from nodulates of the leguminous trees Gliricidia sepium, a natural host of Rhizobium tropici. Arch. Microbiol. 178:161-164.

Almeida, R. P. y A. H. Purcell, 2003. Transmission of Xylella fastidiosa to grapevines by Homalodisca coagulata (Hemiptera: Cicadellidae). J. Econ. Entomol. 96(2):264-271.

Araújo, W., W. Maccheroni, C. Aguilar, P. Barroso, H. Saridakis y J. Azevedo, 2001. Variability and interactions between endophytic bacteria and fungi isolated from leaf tissues of citrus rootstocks. Can. J. Microbiol. 47:229-236.

Araújo, W. J. Marcon, W. Maccheroni, J. Elvas, J. Vourde y J. Azevedo, 2002. Diversity of endophytic bacterial populations and their interaction with Xylella fastidiosa in citrus plants. Appl. Environ. Microbiol. 68(10):4906-4914.

Azevedo, J., W. Maccheroni, J. Pereira y W. Araújo, 2000. Endophytic microorganisms: a review on insect control and recent advances on tropical plants. Electronic Journal of Biotechnology <http://www.ejbiotechnology.info/content/vol3/issue1/full/4/index.html>.

Bahar, A. y Z. Demirgab, 2007. Isolation of pathogenic bacteria from Oberea linearis (Coleoptera:Cerambyciadae). Biologia 62(1):13-18.

Balows, A. H. Tryper, M. Dworkin, W. Harder y K. Schleifer, 1992. The Prokaryotes. Second edition. Volumen I-IV.

Bell, A., J. Lopez, J. Esquivel, E. Medrano y J. Mauney, 2005. Isolation of cottonseed-rooting Pantoea spp. from stink bugs and plants bugs. Memories of Proceedings of the Beltwide Cotton Conferences January 4-7 http://www.ars.usda.gov/research/publications/publications .htm?SEQ_NO_115=176993>.

Beretta, M., R. Harakava y C. Chagas, 1996. First report of Xylella fastidiosa in coffee. Plant Dis. 80:821.

Bíliková, K., G. Wu y J. Simúth, 2001. Isolation of a peptide fraction from honeybee royal jelly as a potential antiforulbrood factor. Apidologie 32:275-283.

Blake, B., T. Shu-Jen, H. Shaikh, M. Blua y T. A. Millar, 2004. Evaluation of methods for extracting Xylella fastidiosa DNA from the Glassy-Winged Sharshooter. J. Econ. Entomol. 97(3):757-763.

Bradbury, J. F., 1991. Descriptions or pathogenic fungi and bacteria No. 1049. CAB International, Wallingford, UK.

Brodbeck, B. y P. Andersen, 2006. Status of xylem limited bacterium Xylella fastidiosa in Puerto Rico. NFREC NEWS. North Florida Research and Education Center, University of Florida. 8(19): $3 \mathrm{p}$.

Brodbeck, P., M. Zapata, S. Oden, Y. Mariño y P. Andersen, 2006. Potential leafhoppers vectors of Xylella fastidiosa in Puerto Rico. Proc. Caribbean Food Crops Society 42(2):219.

Caesar, A. y R. Kremer, 2004. Bacterial communities associated with a flea beetle used for the biological control of the perennial leed Euphorbia esula virgata. Memories of 


\section{MARIÑO-CÁRDENAS \& ZAPATA/ BACTERIAS EN CICADÉLIDOS}

Xi symposium on Biological Control of Weeds. April 15, 2004. <http://ars.usda.gov/ research/publications/publications.htm?SEQ_NO_115 $=159417>$.

Cambell, C., D. Mummey, E. Schmidtmann y W. Wilson, 2004. Culture-independent analysis of midgut microbiota in the arbovirus vector, Culicoides sonorensis (Diptera: Ceratopogonidae). J. Med. Entomol. 41(3):340-348.

Céu, M., V. Várzea, L. Guerra, H. Gil, D. Fernandez, A. Petitot, B. Bertrand, P. Lashermes y N. Nicole, 2006. Coffee resistance to the main disease: lead rust and coffee berry disease. Braz. J. Plant Physiol. 18(1):119 -147.

Chacón, C., M. Montero, J. Hartung, W. Li, L. Garita y C. Rivera, 2006. Isolation, description and identification bacteria associated with diseased coffee and avocado from Costa Rica. Phytopathology 96(6):S142.

Costa, H., E. Raetz, T. Pinckard, C. Gispert, R. Hernández-Martínez, C. Dumenyo y D. Cooksey, 2004. Plants hosts of Xylella fastidiosa in and near south California vineyards. Plant Dis. 88:1255-1261.

Departamento de Agricultura, 2008. Ingreso bruto agrícola de Puerto Rico. 2006/2007. Oficina de Estadísticas Agrícolas. Santurce, Puerto Rico.

Enright, M. y C. Griffin, 2004. Specificity of association between Paenibacillus spp. and the entomopathogenic nematodes, Heterorhabditis spp. Microbial Ecology 48(3):414-423.

Evans, J., 2004. Transcriptional immune reponses by honey bee larvae during invasion by the bacterial pathogen, Paenibacillus larvae. J. Invertebr. Pathol. 85(2):105111.

Evans, J. y T. Armstrong, 2005. Selective screening for honey bee bacterial symbionts that inhibit a key bacterial pathogen, Paenibacillus larvae. J. Apicul. Research 44:168-171.

Franco, H., H. Alves, I. Soares, F. Nunes y W. Bettiol, 2006. Bioprospecting endophytic bacteria for biological control of coffee leaf rust. Sci. Agric. 63(1):22-29.

Galvis, C. A., J. E. Leguizamón, A. L. Gaitán, J. F. Mejía, E. Alvarez y J. Arroyave, 2007. Detection and identification of a group 16SrIII-related phytoplasma associated with coffee crispiness disease in Colombia. Plant Disease 91:3:248-252.

Gaur, R., N. Shani, J. Kawaljeet, B. Rossi y M. Aragno, 2004. Diacetyl phloroglucinol-producing Pseudomonas do not influence AM fungi in wheat rhizosphere. Curr. Sci. 86:453-457.

Gitaitis, R., R. Walcott, M. Wells, J. Diaz y F. Sanders, 2003. Transmission of Pantoea ananatis, causal agent of center rot of onion, by tobacco thrips, Frankliniella fusca. Plant Dis. 87:675-678.

Hallmann, J., A. Quadt-Hallmann, W. Mahaffee y J. Kloepper, 1997. Endophytic bacteria in agricultural crops. Can. J. Microbiol. 43:895-914.

Hartung, J., J. Berreta, R. Brlansky, J. Spisso y R. Lee, 1994. Citrus variegated chlorosis bacterium: axenic culture, pathogenicity, and serological relationships with other strains of Xylella fastidiosa. Phytopathology 84:591-597.

Hayward, A., 1983. Primary differentiation of the genera of plant pathogenic bacteria. Plant Disease A Diagnostic Guide. Edited by P. C. Fahay and G. J. Persley. Academic Press, Sidney, Australia. 13-26 p.

Hill, B. y A. Purcell, 1995. Acquisition and retention of Xylella fastidiosa by an efficient vector, Graphocephala atropunctata. Phytopathology 85:209-212.

Holst, E., J. Rollof, L. Larsson y J. P. Nielsen, 1992. Characterization and distribution of Pasteurella species recovered from infected humans. J. Clin. Microbiol. 30:29842987.

Hopkins, D., 1989. Xylella fastidiosa: Xylem-limited bacterial pathogens of plants. Annual Review Phytopathology 27:271-290. 
Infostat, 2006. Infostat, version 2006. Grupo Infostat, FCA, Universidad Nacional de Córdoba. Primera Edición. Editorial Brujas. Córdoba, Argentina.

Jaffe, K., F. Caetano, P. Sánchez, J. Hernández, L. Caraballo, J. Vitelli, W. Monsalve, B. Dorta y V. Rodríguez, 2001. Sensitivity of ant (Cephalotes) colonies and individuals to antibiotics implies feeding symbiosis with gut microorganisms. Can. J. Zool. 79:1120-1124.

Krechel, A., A. Faupel, J. Hallmann, A. Ulrich y G. Berg, 2002. Potato-associated bacteria and their antagonistic potential towards plant-pathogenic fungi and plant-parasitic nematode, Meloidogyne incognita (Kofoid \& White) Chitwood. Can. J. Microbiol. 48:772-786.

Kloepper, J., C. Ryu y S. Zhang, 2004. Induced systemic resistance and promotion of plant growth by Bacillus spp. Phytopathology 94:1259-1266.

Krieg, N. y J. Holt, 1984. Bergey's Manual of Systematic Bacteriology. Volume 1. 512-514.

Kunitsky, C., G. Osterhout y M. Sasser, 2006. Identification of microorganisms using fatty acid methyl ester (FAME) analysis and the midi sherlock microbial identification system. Encyclopedia of Rapid Microbiological Methods. Volumen III. 1-18 p.

Kuzina, L., J. Peloquin, D. Vacek y T. Millar, 2004. Isolation and identification of bacteria associated with adult laboratory mexican fruit flies, Anastrepha ludens (Diptera: Tephritidae). Current Microbiology 48(2):290-294.

Lacava, P., W. Araújo, J. Marcon, W. Maccheroni y J. Azevedo, 2004. Interaction between endophytic bacteria from citrus plants and the phytopathogenic bacteria Xylella fastidiosa, causal agent of citrus-variegated chlorosis. Letters in Applied Microbiology 39:55-59.

Lacy, G. y F. Lukezic, 2003. Pathogenic prokaryotes, plant pathology: concepts and laboratory exercises. CRC Press LLC. 41-52.

Lalande, R., N. Bissonnette, D. Coutlée y H. Antoun, 1989. Identificiation of rhizobacteria from maize and determination of their plant-growth promoting potential. Plant and Soil. 115:7-11.

Li, W., W. Pria, D. Texeira, V. Miranda, A. Franco, M. Costa, C. He, P. Costa y J. Hartung, 2001. Coffee leaf scorch caused by a strain of Xylella fastidiosa from Citrus. Plant Dis. 85:501-505.

Lopes, J., 1996. Mecanismos de transmissão of Xylella fastidiosa por eigarrinhas. Laranja 17(1):79-92.

Maciel, M., 2005. Diversidade de bactérias endofíticas de raízes de milho (Zea mays L.) e potencial para promoção de crescimento. Tese $\mathrm{PhD}$. Universidade Federal de São Carlos. São Carlos, Brasil. 132 pp.

Mariño, Y., 2007. Identificación de bacterias en cicadélidos vectores potenciales de $X y$ lella fastidiosa Wells et al. que se alimentan del tejido vascular de plantas de café Coffea arabica L. en tres localidades de Puerto Rico. Tesis MS. Universidad de Puerto Rico. Mayagüez, Puerto Rico. 160 pp.

Mariño, Y., M. Zapata y B. Brodbeck, 2007. Identification of insects (Hemiptera: Auchenorryncha) potencial vectors of Xylella fastidiosa Wells et al. in coffee plants of three localities of Puerto Rico. Memories of XII Sigma Xi Student poster day. Mayagüez, P.R., April 26.

Martin, W., M. Grisham, C. Kenerly, W. Sterling y P. Morgan, 1987. Microorganism associated with cotton fleahopper, Pseudatomoscelis seriatus (Heteroptera:Miridae). Ann. Entomol. Soc. Am. 80:251-255.

Meneguim, A., L. Akemi y R. Pedreida, 2001. Levantamento da fauna de homópteros vectores de Xylella fastidiosa em viveiros de mudas de cafeeiro (Coffea arabica L.). PROMECAFE, Boletin 91-92:23-24. 
Mitchell, P., 2004. Heteroptera as vectors of plant pathogens. Neotrop. Entomol. 33(5):519-545.

Monroig, M., 2007. Ecos del café. <http://academic.uprm.edu/mmonroig/>. August, 2007.

Mundell, N., 2005. Phylogenetic analysis of Kentucky strains of Xylella fastidiosa. Tesis M.S. College Agriculture. University of Kentucky, Lexington. 103 pp.

Newman, K., R. Almeida, A. Purcell y S. Lindow, 2004. Cell-cell signaling controls Xylella fastidiosa interactions with both insects and plants. Microbiology 101(5):1737-1742.

Nomé, S., B. Raju, A. Goheen, G. Nyland y D. Docampo, 1980. Enzyme-linked immunosorbent assay for Pierce's disease bacteria in plant tissues. Phytopathology 70:271290.

Purcell, A. y D. Hopkins, 1996. Fastidious xylem-limited bacterial plant pathogens. Ann. Rev. Phytopa. (34):131-151.

Redak, R., A. Purcell, J. Lopes, M. Blua, R. Mizell y P. Andersen, 2004. The biology of xylem fluid-feeding insect vectors of Xylella fastidiosa and their relation to disease epidemiology. Ann. Rev. Entomol. 49:243-270.

Reva, O., V. Smirnov y B. Peterson, 2002. Bacillus endophyticus sp. nov., isolated from the inner tissues of cotton plants (Gossypium sp.). Intern. J. System. Evol. Microbiol. 52:101-107.

Rodríguez, M., 2003. Xylella fastidiosa (Wells) como patógeno de café en los países tropicales. PROMECAFE. Boletín Número 9:13-28.

Santos, C., J. Lopes, W. Araújo y J. Azevedo, 2004. Estudio molecular y biológico de la interacción entre bacterias endofíticas e insectos vectores (Insecta, Cicadellinae), de Xylella fastidiosa, el agente causal de la clorosis variegada de los citrus. V Encuentro Larionamericano y del Caribe de Biotecnología Agrícola (Redbio). República Dominicana. Junio 21-25.

Schaad N., J. Jones y W. Chun, 2001. Laboratory guide for identification of plant pathogenic bacteria. 3rd. edition, pág. 201-213.

Sezen, K., I'. Demir, H. Katl y Z. Demirbağ, 2005. Investigations on bacteria as a potential biological control agent of summer chafer, Amphimallon solstitiale L. (Coleoptera: Scarabidae). J. Microbiol. 43(5):463-468.

Smitley, D. y N. Rothwell, 2003. How the use of chlorothalonil on golf courses impacts Paenibacillus sp., a pathogen of Ataenius spretulus (Coleoptera: Scarabidae). J. Economic. Entomol. 96(3):792-797.

Spiteller, D., K. Dettner y W. Boland, 2000. Gut bacteria may be involved in interactions between plants, herbivores and their predators: microbial biosynthesis of $\mathrm{N}$ - acylglutamine surfactants as elicitors of plant volatiles. Biol. Chem. 381:755-762.

Tilak, K., N. Ranganayaki, K. Pal, R. De, A. Saxena, C. Shekhar, S. Mittal, A. Tripathi y B. Johri, 2005. Diversity of plant growth and soil health supporting bacteria. Curr. Sci. 89(1):136-150.

Tóth, E., É. Hell, G. Kovács, A. Borsodi y M. Márialigeti, 2006. Bacteria isolated from the different developmental stages and larval organs of the obligated parasitic fly, Wohlfahrtia magnifica (Diptera: Sarcophagidae). Microbial Ecology (15):13-21.

Urhan, O., 1950. Algunas ideas sobre el problema de la Crespera. Cenicafé 1:29-35.

Van der Wolf, J., J. G. Elphinstone, D. Stead, M. Metzler, P. Müller, A. Hukkanen y R. Karjalainen, 2005. Epidemiology of Clavibacter michiganensis subsp. Sepedonicus in relation to control bacterial ring rot. Plant Research International B.V., Wageningen. Report 95. 38 pp.

Vargas, L., E. Sánchez, M. Vargas, A. Solorzano, F. Hernández, H. Iwasawa y E. Freer, 2002. Bacterial present in the xylem of coffee (Rubiaceae: Coffea arabica) with "Crespera" disease. Rev. Biol. Trop. 50(1): 45-48. 
Vega, F., M., Pava-Ripoll, F. Posada y J. Buyer, 2005. Endophytic bacteria in Coffea arabica L. J. Basic Microbiol, 45 (5):371-380.

Wang, Z., J. Comstock, E. Hatziloukas y N. Schaad, 1999. Comparison of PCR, BIO-PCR, DIA, ELISA and isolation on semiselective medium for detection of Xanthomonas albileans, the causal agent of leaf scald of sugarcane. Plant Pathology 48:245-252.

Wells, J. M., B. C. Raju, H. Y. Hung, W. G. Weisburg, L. Mandelco y D. J. Brenner, 1987. Xylella fastidiosa gen. nov.:Gram-negative, xylem-limited, fastidious plant bacteria related to Xanthomonas spp. Int. J. Syst. Bacteriol. 37:136-143.

Wells, M., R. Gitaitis y F. Sanders, 2002. Association of tobacco thrips Frankliniella fusca (Thysanoptera: Thripidae) with two species of bacteria of the genus Pantoea. Annals Entomo. Soc. Am. 95(6):719-723.

Yaman, M., R. Nalçacioğlu y Z. Demirbağ, 2002. Studies on bacterial flora in the population of the fall webworm, Hyphantria cunea Drury. (Lep., Arctiidea). J. App. Entomol. 126(9):470-474.

Zapata, M., 2007. Investigación sobre la identificación de la bacteria Xylella fastidiosa y otras endofitas asociadas al sistema vascular en café y cítricos en Puerto Rico. Memorias Foro sobre café sostenible en Puerto Rico. 39-41.

Zinniel, D., P. Lambrecht, N. Harris, Z. Feng, D. Kuczmarski, P. Higley, C. Ishimaru, A. Arunakumari, G. Barletta y A. Vidaver, 2002. Isolation and characterization of endophytic colonizing bacteria from agronomic crops and prairie plants. Appl. Environ. Microbiol. 68:2198-2208.

Zurdo, J., E. Velásquez, M. Lorite, G. Brelles, E. Schröder, E. Bedmar, P. Mateos y E. Martínez, 2004. Identification of fast-growing rhizobia nodulating tropical legumes from Puerto Rico as Rhizobium gallicum and Rhizobium tropici. Syst. and Appl. Microbiol. 27:469-477. 
